\title{
THE DEVELOPMENT OF A NEW ADSORPTION-DESORPTION DEVICE
}

\author{
L'udmila Gabrišová ${ }^{a}$, Peter Peciar $^{a}$, Oliver Macho ${ }^{a}$, Martin Juriga $^{a}$, \\ Paulína Galbavá ${ }^{b}$, Žofia Nižnanská ${ }^{b}$, Róbert Kubinec $^{b}$, IVAn VAlent ${ }^{c}$, \\ MARIÁN PECIAR ${ }^{a}$
}

a Slovak University of Technology in Bratislava, Faculty of Mechanical Engineering, Institute of Process Engineering, Námestie Slobody 17, 81231 Bratislava, Slovakia

${ }^{b}$ Comenius University in Bratislava, Faculty of Natural Sciences, Institute of Chemistry, Mlynská dolina, Ilkovičova 6, 84215 Bratislava, Slovakia

${ }^{c}$ Comenius University in Bratislava, Faculty of Natural Sciences, Department of Physical and Theoretical Chemistry, Mlynská dolina, Ilkovičova 6, 84215 Bratislava, Slovakia

* corresponding author: ludmila.gabrisova@stuba.sk

\begin{abstract}
The aim of this work was to construct a new adsorption-desorption device based on the principle of separation of volatile organic compounds, e.g., ethanol. As an adsorbent, it is possible to use granulated activated carbon (GAC) in the adsorption and desorption process. In this study, two kinds of GACs were used and marked as GAC1 and GAC2. A particle size distribution and water vapuor sorption for the selected GACs were measured. An experiment with distilled water was performed as a preliminary study of the new device's functionality. After the determination of the time necessary for the adsorption and desorption, the experiments were carried out with a model mixture $(5 \% \mathrm{v} / \mathrm{v}$ ethanol-water mixture), which resulted in a product with the ethanol content of $39.6 \%$. The main advantage of this device would be the potential competition of conventional distillation.
\end{abstract}

KEYWORDS: Adsorption, desorption, air stripping, activated carbon, ethanol.

\section{INTRODUCTION}

In both, industry and science, there is an increasing effort to produce simple devices, for the separation of volatile organic compounds (VOC) [1-3]. In the light of this, devices which are capable of adsorbing VOCs and subsequently desorbing them, are being constructed. The desorption process is decisive in many cases because it is necessary to obtain unchanged adsorbed compounds (surface of the sorbent cannot react with the adsorbate) 4. After the desorption, compounds are analysed and stored for further use.

Ethanol is the most discussed compound in this context as it is the main product of many fermentation processes [5] produced by yeasts as their metabolism by-product. The yeast transforms saccharides into ethanol and other VOCs. The content of VOCs and other fermentation products depends on the nature of the raw material (fruit, corn, etc.) [9 13]. Generally, distillation is the most common way of separating ethanol from the fermentation broth. This process is energy-demanding, and hence, there is a demand for another alternative device [14. In most production processes, ethanol is in a liquid matrix (fermentation broth). There are many ways to separate ethanol from these matrices, for example, by a conventional distillation or by an adsorption onto the adsorbent directly from the liquid [15]. Another method of separation is the adsorption of ethanol in a gaseous state [16].
Gas with the ethanol content is created by gas stripping. This technique often takes place at laboratory temperature. The gas used for the gas stripping should be inert to compounds (VOC) in a liquid matrix. Carbon dioxide, nitrogen or air are, therefore, the commonly used gases. Moreover, the absence of interaction with a separation adsorbent is another important requirement [1, 6, 8, 12, 13, 17, 18. Activated carbon, polymeric resins and zeolites can be used as an adsorbent in this kind of separation method [19] 22 . The main advantage of activated carbon is its extensive specific surface area, price and availability 23 .

Desorption, a reverse process of adsorption, is an important part of these kinds of separation methods. Desorption of adsorbed compounds is facilitated by a temperature increase or pressure decrease, which are two of the most frequently used techniques [24-28]. In our study, we used granulated activated carbon as the adsorbent and air as the stripping gas. The desorption was performed by increasing the temperature.

\section{Methods}

\subsection{EXPERIMENTAL MATERIAL}

$96 \%$ ethanol purchased from MIKROCHEM s.r.o. (Pezinok, Slovakia) was used for the preparation of the model mixture. For the gas adsorption, two kinds of granulated activated carbon were used, GAC1 
and GAC2, which were purchased from SandSystem s.r.o. (Klimovice, Czech Republic) and Alchimica s.r.o. (Prague, Czech Republic) respectively.

\subsection{ANALYSIS OF EXPERIMENTAL DATA}

The ethanol concentration before and after the adsorption was calculated from the density of the model mixture, which was determined by DMA 48 digital density meter (Anton Paar, Austria) at a constant temperature of $25^{\circ} \mathrm{C}$. The volume of the sample for the density determination was $3 \mathrm{ml}$. The ethanol concentration in the condensate was determined using the same method. The particle size distribution of GAC1 and GAC2 was measured by a PartAn 3D particle size analyzer (Microtrac GmbH, Germany). The water vapour adsorption was determined by an Aquadyne DVS (Quantachrome, UK) at isothermal conditions.

\subsection{EXPERIMENTAL DEVICE - CONSTRUCTION AND PROCESS DESCRIPTION}

Our device (Fig. 1) works on the principle of adsorption and desorption of gases or compounds present in a gaseous state at laboratory temperature. The device works in two phases. Firstly, the gas is adsorbed onto the adsorbent in the device at laboratory temperature. Secondly, the adsorbed gas is desorbed at a high temperature $\left(150^{\circ} \mathrm{C}\right)$. This phase also includes a condensation of the desorbed gas. This device is especially designed for the adsorption of VOC from matrices with a low VOC content and subsequent formation of a product with a high VOC content by desorption and condensation. The new device consist of the following components: an HG-120 air blower (Zhejiang, China), a HAAKE N6 heating circulator (Karlsruhe, Germany), a HAKKE DC1 refrigerating circulator (Karlsruhe, Germany), a UPLS 3 flowmeter (Prague, Czech Republic) and an ALMEMO 5690-1M measuring temperature station (Holzkirchen, Germany). The glass components (heat exchangers, stock vessel, flask, etc.) of the device were of the brand Simax.

The new adsorption-desorption device works in a closed cycle, which is achieved by the air blower. The path of the gas flow in the device is indicated by Roman numerals (I-IX) (Fig. 1).

Adsorption: Stripping gas (air) flows from the air blower into the stock vessel, which is filled with liquid (path I-III). This liquid (model mixture or distilled water) is stripped by the stripping gas (air) in the stock vessel. In this way, the molecules are converted from liquid to gaseous state. Subsequently, the gas flows through the first heat exchanger (IV) into the second heat exchanger (V) filled with the GAC. Here, adsorption takes place at laboratory temperature and the gas containing molecules from the liquid is adsorbed onto the GAC. The molecules in the gas, which are not adsorbed, flow through the condenser back to the air blower (path VI-IX) and the adsorption circuit is repeated until the GAC is saturated. It is important to mention that both heat exchangers (IV and V) coupled with a heating circulator are interconnected. At the beginning of the desorption process, the heating circulator is turned on and set to $150{ }^{\circ} \mathrm{C}$ (thermal desorption). The condenser (VII) is connected to the refrigerating circulator, which is set to $-25^{\circ} \mathrm{C}$ (condensation of desorbed gas). In each experiment, the stripping gas flow rate was controlled by a flowmeter (F) set at $5 \mathrm{l} / \mathrm{min}$. The temperature was measured with six thermocouples by a real-time measuring station. The thermocouples' location is in Fig. 1 and marked as $T 1-T 6$.

Desorption: Adsorption is finished after a complete saturation of the GAC. The liquid from the stock vessel is removed through a port for liquid removal (Fig. 1). The air blower serves as a gas propeller in the desorption process. For this reason, desorbed molecules (gas) are transported to the condenser (VII) where they condense and accumulate in the flask fixed at the end of the condenser. Very important is the fact that the heating circulator and refrigerating circulator are turned on, only during the desorption.

\section{Results AND Discussion}

\subsection{Characterization of GaC}

The particle size of the adsorbent is one of the parameters which affects the processes of adsorption and desorption. Hence, the particle size distribution for the chosen GACs was measured. The small particle size (powdered activated carbon, PAC) of the adsorbent negatively affects the gas flow in the packed bed. However, the gas flow through the adsorbent as GAC is better than through the PAC, thanks to the lower influential resistance during the flow 30 .

The particle size distribution was measured by PartAn 3D. PartAn 3D is a device, which analyzes the size and shape of particles by an integrated high-speed camera system. The falling solid particles are captured by the camera and the acquired data are evaluated by the software. The result of the analysis is a graph, GACs particle size distribution, which is shown in Fig. 2 The GAC particle size distribution shows that the majority of GAC1 and GAC2 particles have a diameter in the range of $2-2.75 \mathrm{~mm}$ and $1.25-2 \mathrm{~mm}$, respectively. Hence, GAC2 can create a higher resistance during the adsorption and desorption process. As a consequence, there can be a worse transfer of the gas flow between GAC2 particles.

The second step in the production of activated carbon is its activation. After this step, activated carbon becomes more hydrophilic [26, 31, 33]. Due to this property of activated carbon, a maximum possible adsorbed amount of water for GAC1 and GAC2 was determined by the water vapour station Aquadyne DVS. The determination of water vapour sorption, by Aquadyne DVS, is important because a content of water in the stripped model mixture is significant (Fig. 3). Aquadyne DVS is a device that measures 


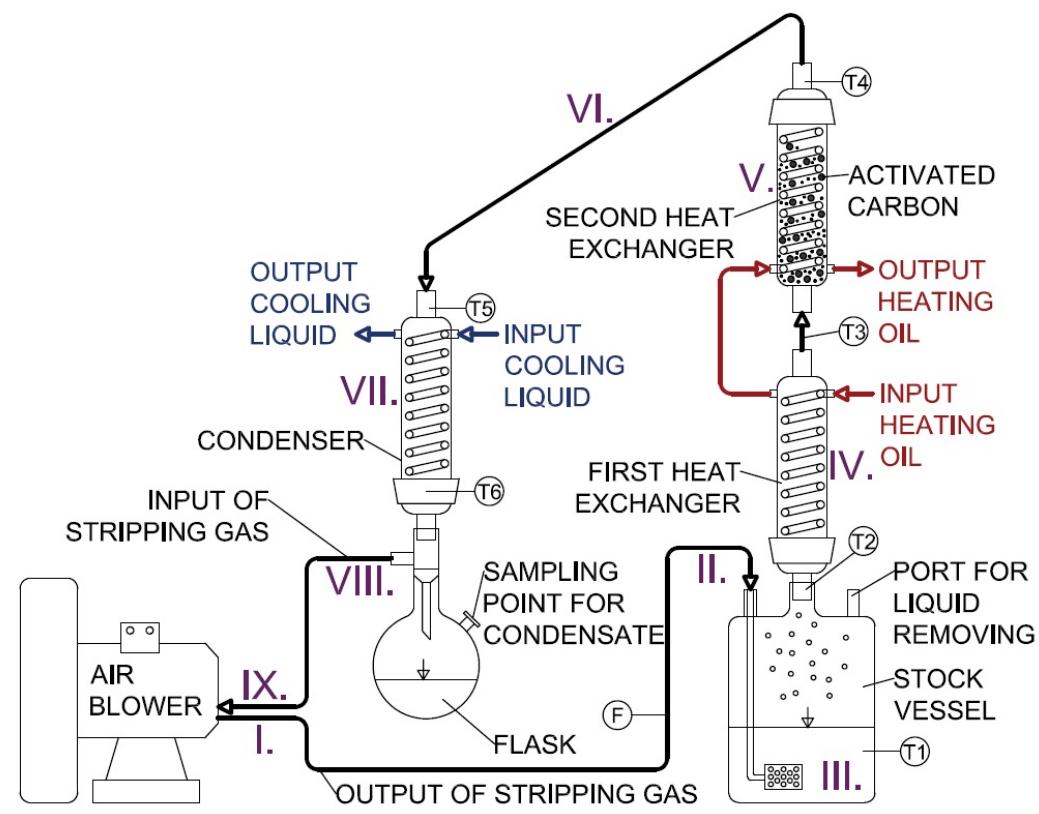

FIGURE 1. Scheme of the new adsorption-desorption device [29].

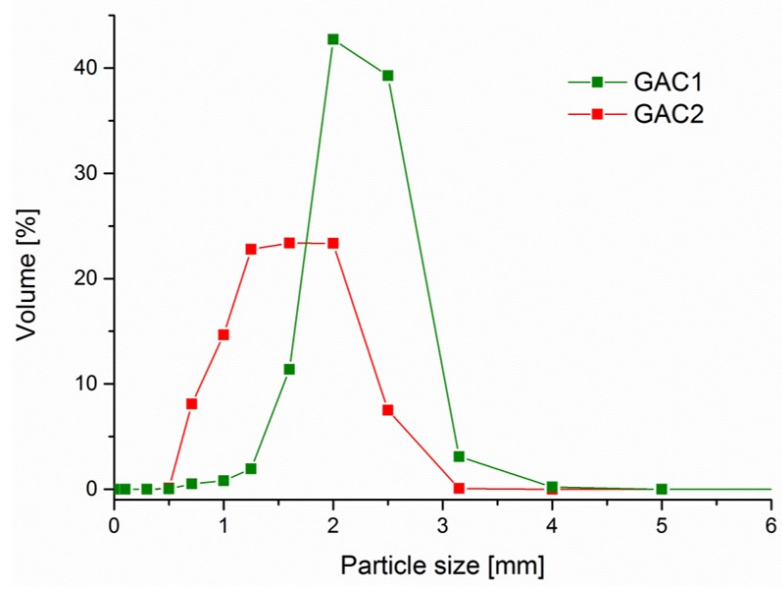

Figure 2. The particle size distribution of GAC1 and GAC2.

the change of the initial sample mass $(50 \mathrm{mg})$ as a function of relative humidity. The GACs water vapour sorption graph, where the GAC's weight increased as a function of rising relative humidity and is stable after the saturation, is shown in Fig. 3. The saturation point of GAC1 was at $95.1 \%$ of relative humidity and the weight increased by $40.1 \%$ compared to the initial sample. The GAC2 saturation point was at $93.8 \%$ of relative humidity and the weight of the sample increased by $32.3 \%$. The shapes of the adsorption and desorption curves are the same for GAC1 and GAC2, which suggests the same progress of both processes. GAC1, in comparison to GAC2, can adsorb a higher amount of water vapour, which is clear from the $y$ axis expressing the percentage change of mass. It is a consequence of a higher specific surface area of GAC1.

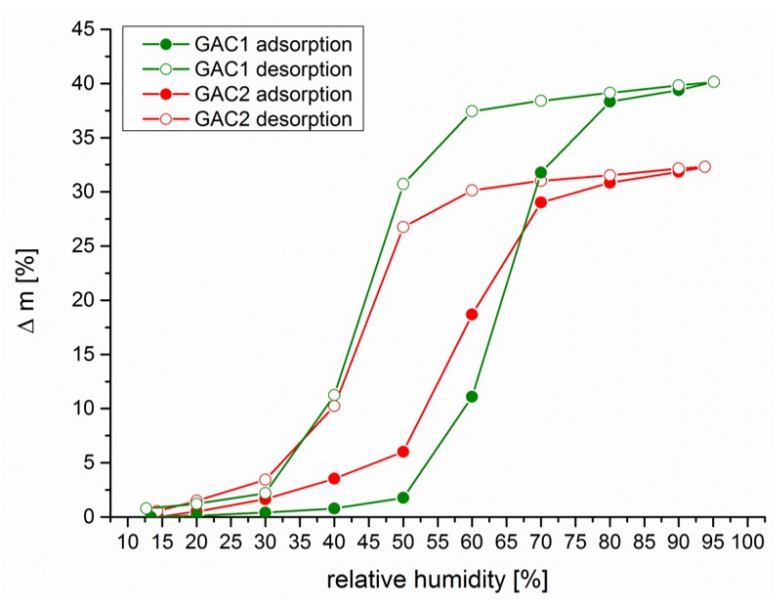

FIgURE 3. The water vapour adsorption and desorption graph of GAC1 and GAC2.

The difference in the specific surface area of the GACs is approximately $54 \mathrm{~m}^{2} / \mathrm{g}$.

\subsection{Preliminary Study}

For the determination of the necessary adsorption time and basic observation of temperature in the device, the experiment with distilled water was performed. General conditions and specifications, which were applied for each experiment, are described in this subchapter. The volume of the liquid in the stock vessel was $997 \mathrm{ml}$ ( $3 \mathrm{ml}$ from $1000 \mathrm{ml}$ for the density determination) per experiment. The second heat exchanger was filled with $80 \mathrm{~g}$ of GAC with $\leq 1 \%$ residual moisture in each experiment. The temperature in the device was measured by six thermocouples $(T 1-T 6)$. Thermocouple $T 1$ measures the temperature of the liquid (the model 


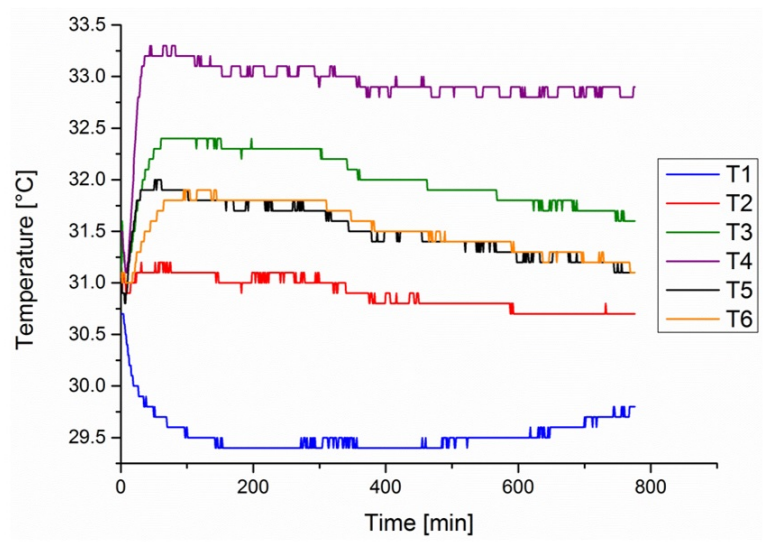

FiguRE 4 . The temperature readings of thermocouples $T 1-T 6$ during the adsorption process with distilled water.

mixture or distilled water), the other thermocouples measure the temperature of the gas. Fig. 4 shows the temperature readings obtained during the adsorption experiment with distilled water. This figure shows that after approximately 12 hours, the temperature measured by thermocouples $T 2-T 6$ is stable. The decrease in the temperature in the liquid is caused by the gas stripping during the adsorption. Gas Stripping, in this case, is an endothermic desorption process. However, the adsorption is an exothermic process 3436. The increase in the temperature of the distilled water in the stock vessel (curve of thermocouple $T 1$ ) is caused by the saturation of the adsorbent. Hence, the time for the adsorption was set to 12 hours. The time required for the desorption, determined by the formation of condensate in the condenser, was 1 hour.

\subsection{Model Experiments}

For a confirmation of our adsorption-desorption device's functionality, three repeated experiments for each kind of GAC using the same conditions were performed. An ethanol-water mixture, with ethanol concentration of $5 \% \mathrm{v} / \mathrm{v}$, was used as the model mixture. The location and temperature measurement by thermocouples were identical as in the preliminary study.

During the adsorption in model experiments, we observed significant temperature changes measured by thermocouples $T 1$ and $T 4$. Temperature readings of thermocouples $T 1$ and $T 4$ for GAC1 and GAC2, obtained during the adsorption of the gas created from the model mixture, are shown in Fig. 5 The curve of temperature readings measured by thermocouple $\mathrm{T} 1$ has the same course as the temperature record of $T 1$ for distilled water (the decrease of temperature during adsorption and the increase of temperature after GAC saturation). The thermocouple $T 4$ temperature reading (Fig. 5) has two significant peaks - an increase in temperature. The increase in temperature behind the fixed bed of the adsorbent is caused by the adsorption of the gas. The presence of the two

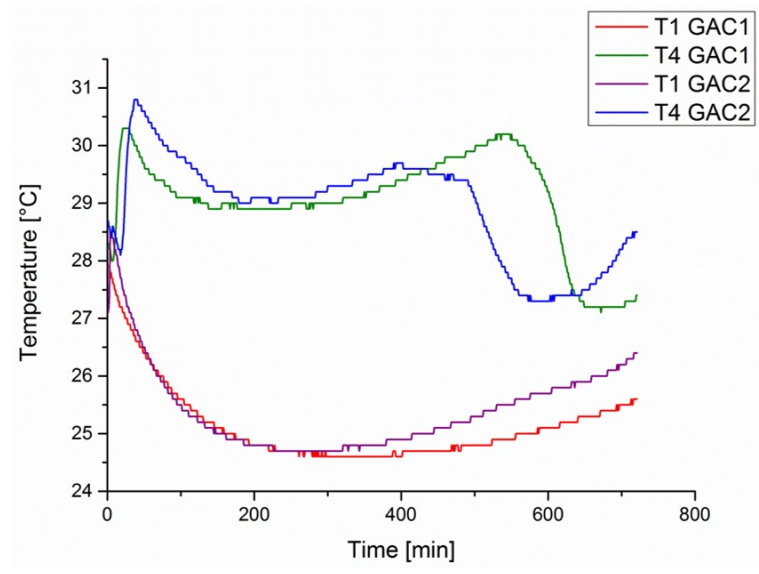

Figure 5. The comparison of thermocouples, $T 1$ and $T 4$ temperature readings during the adsorption of the gas created from $5 \%$ ethanol-water mixture.

peaks is a consequence of the heat release during the adsorption of ethanol and water.

The method for the determination of the ethanol concentration is described in the part Analysis of experimental data. The results of the adsorption, for both types of GAC, are listed in Table 1 and Table 2 in the part ADSORPTION. As mentioned above, the desorption was performed for one hour at a high temperature. Afterwards, the condensate was removed from the device through the sampling point of condensate Fig. 1. The values for the ethanol concentration and the volume of condensate for each experiment are listed in Table 1 and Table 2 in the part DESORPTION. After the desorption process, the second heat exchanger is emptied and the GAC weighed. From the values listed in Table 1 and Table 2 it is clear that GAC1 can produce condensate with a higher concentration of ethanol and volume than GAC2. The condensate volumes correspond to $\Delta V_{M M}$ values, which represent the change of the model mixture volume after the adsorption. The difference between the condensate volume and $\Delta V_{M M}$ depends on several factors: desorption is not complete, a part of the gas volume created by gas stripping stays in the device's dead volume after the adsorption (saturation of the GAC), and some volume of the condensed gas stays on the walls of the condenser after the desorption.

A theoretical interpretation of the obtained experimental data will be the subject of a future analysis. At this stage, we merely suggest some possible approaches. It is useful to assess the gas stream composition leaving the stock solution. Assuming that the partial pressures of ethanol $\left(p_{E}\right)$ and water $\left(p_{W}\right)$ above the model mixture correspond to the equilibrium vapour pressures, the $p_{E}$ and $p_{W}$ are given by the Henry's and Raoult's laws, respectively. However, such an approach provides upper limits only, as the vapor-liquid equilibrium is not precisely specified in gas-stripping systems [37]. Instead, a two-film mass transfer model [38, 39] for non-equilibrium volatilization processes 


\begin{tabular}{ccccccc}
\hline EXPERIMENT & \multicolumn{3}{c}{ ADSORPTION } & \multicolumn{2}{c}{ DESORPTION } \\
\hline & $\begin{array}{c}V_{M M} \\
{[\mathrm{ml}]}\end{array}$ & $\begin{array}{c}E t O H_{A 1} \\
{[\%]}\end{array}$ & $\begin{array}{c}\Delta V_{M M} \\
{[\mathrm{ml}]}\end{array}$ & $\begin{array}{c}E t O H_{A 2} \\
{[\%]}\end{array}$ & $\begin{array}{c}V_{C} \\
{[\mathrm{ml}]}\end{array}$ & $\begin{array}{c}E t O H_{C} \\
{[\%]}\end{array}$ \\
\hline 1. & 997 & 5.0 & 32.5 & 3.5 & 28.5 & 39.6 \\
2. & 997 & 5.0 & 31.0 & 3.6 & 27.0 & 38.1 \\
3. & 997 & 5.0 & 32.0 & 3.5 & 28.5 & 39.2 \\
\hline
\end{tabular}

TABLE 1. The observed values for adsorption and desorption quantities of GAC1.

\begin{tabular}{ccccccc}
\hline EXPERIMENT & \multicolumn{3}{c}{ ADSORPTION } & \multicolumn{2}{c}{ DESORPTION } \\
\hline & $\begin{array}{c}V_{M M} \\
{[\mathrm{ml}]}\end{array}$ & $\begin{array}{c}E t O H_{A 1} \\
{[\%]}\end{array}$ & $\begin{array}{c}\Delta V_{M M} \\
{[\mathrm{ml}]}\end{array}$ & $\begin{array}{c}E t O H_{A 2} \\
{[\%]}\end{array}$ & $\begin{array}{c}V_{C} \\
{[\mathrm{ml}]}\end{array}$ & $\begin{array}{c}E t O H_{C} \\
{[\%]}\end{array}$ \\
\hline 1. & 997 & 5.0 & 31.0 & 3.7 & 27.5 & 33.9 \\
2. & 997 & 5.0 & 30.5 & 3.4 & 27.0 & 34.1 \\
3. & 997 & 5.0 & 31.5 & 3.6 & 26.5 & 34.9 \\
\hline
\end{tabular}

TABLE 2. The observed values for adsorption and desorption quantities of GAC2.

should be applied. This approach requires a knowledge of the mass transfer coefficients values, but those, for our system, have not been determined. Calculated equilibrium partial vapour pressures above the $5 \%(\mathrm{v} / \mathrm{v})$ aqueous solution of ethanol at $25{ }^{\circ} \mathrm{C}$ are $p_{E}=449 \mathrm{~Pa}$ and $p_{W}=3119 \mathrm{~Pa}$. Ignoring the partial pressure of the stripping gas, these values predict a molar fraction of ethanol in the gaseous binary mixture as $12.6 \%$. As the ethanol volume fraction of $5 \%$ corresponds to a molar fraction of $1.59 \%$, the stripping increases the molar fraction of ethanol by a theoretical factor of 7.9. This value agrees with the concentration of ethanol in the condensate of GAC1. For a comparison, the conventional distillation process yields a factor of 9 at the boiling point $\left(95.5{ }^{\circ} \mathrm{C}\right)$ of the $5 \%$ ethanol [40.

\section{Conclusion}

In this article, we describe the design and construction of the new adsorption-desorption device. Basic properties (particle size distribution and water vapour sorption) of commercially available GACs were determined using the PartAn 3D and the Aquadyne DVS. Based on the data from the particle size distribution analysis, GAC1 is assumed to have a better gas flow through the adsorbent bed. The results from the water vapour sorption measurements show that GAC1 can adsorb more mass than GAC2. The experiment with distilled water determined the time necessary for adsorption and desorption. The functionality of the new adsorption-desorption device was confirmed using $5 \%$ ethanol-water mixtures. The content of ethanol $39.6 \%(\mathrm{v} / \mathrm{v})$ in the product represents the efficiency of the separation processes in this device. The ethanol concentration in the product was almost eight times higher than in the initial sample $(5 \% \mathrm{v} / \mathrm{v})$. The main benefit of this device is an innovative approach to removing ethanol from available matrices. This device has a potential to increase the production of ethanol in fermentation processes.

\section{LIST OF SYMBOLS}

$E t O H_{A_{1}}$ Ethanol concentration of the model mixture before adsorption [\%]

$\mathrm{EtOH}_{A_{2}}$ Ethanol concentration of the model mixture after adsorption [\%]

$\mathrm{EtOH}_{C} \quad$ Ethanol concentration of the product after adsorption-desorption process [\%]

$p_{E} \quad$ Partial pressures of ethanol $[\mathrm{Pa}]$

$p_{W}$ Partial pressures of water $[\mathrm{Pa}]$

$V_{C}$ Volume of the product (condensate) after adsorption-desorption process [ml]

$V_{M M}$ Volume of the model mixture in stock vessel before adsorption $[\mathrm{ml}]$

$\Delta V_{M M}$ Volume of the model mixture in stock vessel after adsorption $[\mathrm{ml}]$

\section{ACKNOWLEDGEMENTS}

This work was supported by the Slovak Research and Development Agency under the contract numbers APVV15-0466, APVV-18-0282 and APVV-18-0348. This publication was created on the basis of the major project "ACCORD" (ITMS project code: 313021X329) supported by Operational Programme Research and Development funded by the European Regional Development Fund. The authors wish to acknowledge the Ministry of Education, Science, Research and Sport of the Slovak Republic for the financial support of this research by grant KEGA 036STU$4 / 2020$. This article was created within the grant project "The research of modern unit operations in production of solid and liquid dosage forms with a focus on continuous granulation and lyophilization" from the Grant scheme to support excellent teams of young researchers under the conditions of the Slovak University of Technology in Bratislava. The authors would like to thank Mr. John Peter Blight and M.Sc. Barbora Veselková for the language reviews and editing. 


\section{REFERENCES}

[1] S. Onuki, J. Koziel, W. S. Jenks, et al. Ethanol purification with ozonation, activated carbon adsorption, and gas stripping. Separation and Purification Technology 151:165-171, 2015. DOI:10.1016/j.seppur.2015.07.026

[2] F. Gironi, V. Piemonte. VOCs removal from dilute vapour streams by adsorption onto activated carbon. Chemical Engineering Journal 172(2-3):671-677, 2011. DOI:10.1016/j.cej.2011.06.034.

[3] F. Taylor, M. J. Kurantz, N. Goldberg, J. Craig Jr. Kinetics of continuous fermentation and stripping of ethanol. Biotechnology Letters volume 20(1):67-72, 1998. DOI:10.1023/A:1005339415979

[4] A. J. Fletcher, Y. Yüzak, K. M. Thomas. Adsorption and desorption kinetics for hydrophilic and hydrophobic vapors on activated carbon. Carbon 44:989-1004, 2006. DOI:10.1016/j.carbon.2005.10.020

[5] A. Silvestre-Albero, J. Silvestre-Albero, A. SepúlvedaEscribano, F. Rodríguez-Reinoso. Ethanol removal using activated carbon: Effect of porous structure and surface chemistry. Microporous and Mesoporous Materials 120(12):62-68, 2009. DOI:10.1016/j.micromeso.2008.10.012

[6] G. Ponce, J. Miranda, M. Alves, et al. Simulation, analysis and optimization of an in situ gas stripping fermentation process in a laboratory scale for bioethanol production. Chemical Engineering Transactions 37:295-300, 2014. DOI:10.3303/CET1437050

[7] J. Sonego, D. Lemos, G. Y. Rodriguez, et al. Extractive batch fermentation with $\mathrm{CO}_{2}$ stripping for ethanol production in a bubble column bioreactor: Experimental and modeling. Energy \& Fuels 28(12):7552-7559, 2014. DOI:10.1021/ef5018797

[8] C. Löser, A. Schröder, S. Deponte, T. Bley. Balancing the ethanol formation in continuous bioreactors with ethanol stripping. Engineering in Life Sciences 5(4):325-332, 2005. DOI:10.1002/elsc.200520084

[9] G. M. Walker, G. Stewart. Saccharomyces cerevisiae in the production of fermented beverages. Beverages 2(30):1-12, 2016. DOI:10.3390/beverages2040030.

[10] C. Xue, G.-Q. Du, J.-X. Sun, et al. Characterization of gas stripping and its integration with acetone-butanol-ethanol fermentation for high-efficient butanol production and recovery. Biochemical Engineering Journal 83:55-61, 2014. DOI:10.1016/j.bej.2013.12.003

[11] T. Ezeji, N. Qureshi, H. Blaschek. Microbial production of a biofuel (acetone-butanol-ethanol) in a continuous bioreactor: Impact of bleed and simultaneous product removal. Bioprocess and Biosystems Engineering 36(1):109-116, 2013. DOI:10.1007/s00449-012-0766-5

[12] N. Qureshi, H. Blaschek. Recovery of butanol from fermentation broth by gas stripping. Renewable Energy 22(4):557-564, 2001 DOI:10.1016/S0960-1481(00)00108-7

[13] G. Ponce, J. Neto, S. Santos de Jesus, et al. Sugarcane molasses fermentation with in situ gas stripping using low and moderate sugar concentrations for ethanol production: Experimental data and modeling. Biochemical Engineering Journal 110:152-161, 2016. DOI:10.1016/j.bej.2016.02.007
[14] L. M. Vane, F. R. Alvarez. Membrane-assisted vapor stripping: energy efficient hybrid distillation-vapor permeation process for alcohol-water separation. Journal of Chemical Technology \& Biotechnology 83:1275-1287, 2008. DOI:10.1002/jctb.1941.

[15] L. Li, P. A. Quinlivan, D. R. U. Knappe. Effects of activated carbon surface chemistry and pore structure on the adsorption of organic contaminants from aqueous solution. Carbon 40:2085-2100, 2002. DOI:10.1016/j.watres.2005.01.029.

[16] H. S. Samanta, S. K. Ray. Separation of ethanol from water by pervaporation using mixed matrix copolymer membranes. Separation and Purification Technology 146:176-186, 2015. DOI:10.106/j.seppur.2015.03.006

[17] K. N. Truong, J. W. Blackburn. The stripping of organic chemicals in biological treatment processes. Environmental Progress 3(3):143-152, 1984. DOI:10.1002/ep.670030304

[18] M. Hashi, J. Thibault, F. H. Tezel. Recovery of ethanol from carbon dioxide stripped vapor mixture: Adsorption prediction and modeling. Industrial \& Engineering Chemistry Research 49(18):8733-8740, 2010. DOI:10.1021/ie1002608.

[19] R. Xiong, S. Sandler, D. Vlachos. Alcohol adsorption onto silicalite from aqueous solution. The Journal of Physical Chemistry C 115(38):18659-18669, 2011. DOI:10.1021/jp205312k

[20] J. Delgado, V. Águeda, M. Uguina, et al. Separation of ethanol-water liquid mixtures by adsorption on a polymeric resin sepabeads 207. The Chemical Engineering Journal 220:89-97, 2013. DOI:10.1016/j.cej.2013.01.057.

[21] J. A. Delgado, M. A. Uguina, J. L. Sotelo, et al. Separation of ethanol-water liquid mixtures by adsorption on silicalite. Chemical Engineering Journal 180:137-144, 2012. DOI:10.1016/j.cej.2011.11.026.

[22] J. Vivo-Vilches, A. Perez-Cadenas, F. CarrascoMarín, F. J. Maldonado-Hódar. About the control of VOC's emissions from blended fuels by developing specific adsorbents using agricultural residues. Journal of Environmental Chemical Engineering 3:2662-2669, 2015. DOI:10.1016/j.jece.2015.09.027

[23] E. Wolak, E. Vogt, J. Szczurowski. Chemical and hydrophobic modification of activated WD-extra carbon. Energy Fuels 14:1-8, 2017. DOI:10.1051/e3sconf/20171402033.

[24] J. A. Delgado, V. I. Águeda, M. A. Uguina, et al. Separation of ethanol-water mixtures by adsorption on BPL activated carbon with air regeneration. Separation and Purification Technology 149:370-380, 2015. DOI:DOI:10.1016/j.seppur.2015.06.011.

[25] K. Dettmer, W. Engewald. Adsorbent materials commonly used in air analysis for adsorptive enrichment and thermal desorption of volatile organic compounds. Analytical and Bioanalytical Chemistry 373:490-500, 2002. DOI:10.1007/s00216-002-1352-5

[26] X. Zhang, B. Gao, A. E. Creamer, et al. Adsorption of VOCs onto engineered carbon material: A review. Journal of Hazardous Materials 338:102-123, 2017. DOI:10.1016/j.hazmat.2017.05.013. 
[27] I. K. Shah, P. Pre, B. J. Alappat. Effect of thermal regeneration of spent activated carbon on volatile organic compound adsorption performances. Journal of the Taiwan Institute of Chemical Engineers 45:1733-1738, 2014. DOI:10.1016/j.jtice.2014.01.006

[28] N. Qureshi, S. Hughes, I. Maddox, M. Cotta. Energy efficient recovery of butanol from fermentation broth by adsorption. Bioprocess and biosystems engineering 27(4):215-222, 2005. DOI:10.1007/s00449-005-0402-8

[29] L. Gabrišová, P. Peciar, R. Kubinec. Apparatus for concentrating volatile organic compounds by adsorption and desorption method for concentrating volatile organic compounds by adsorption and desorption. Patent Application Number 50055-2018. Industrial Property Office of the Slovak Republic, Banská Bystrica, Slovakia, 2018.

[30] M. E. Gamal, H. A. Mousa, M. H. El-Naas, et al. Bio-regeneration of activated carbon: A comprehensive review. Separation and Purification Technology 197:345-359, 2018. DOI:10.1016/j.seppur.2018.01.015

[31] M. Jeguirim, M. Belhachemi, L. Limousy, S. Bennici. Adsorption/reduction of nitrogen dioxide on activated carbons: Textural properties versus surface chemistry A review. Chemical Engineering Journal 347:493-504, 2018. DOI:10.1016/j.cej.2018.04.063.

[32] G. F. de Oliviera, R. C. de Andrade, M. A. C. Trindade, et al. Thermogravimetric and spectroscopic study (TG-DTA/FT-IR) of activated carbon from the renewable biomass source babassu. Química Nova 40(3):284-292, 2017. DOI:10.21577/0100-4042.20160191

[33] M. Baysal, K. Bilge, B. Yilmaz, et al. Preparation of high surface area activated carbon from waste-biomass of sunflower piths: Kinetics and equilibrium studies on the dye removal. Journal of Environmental Chemical Engineering 6:1702-1713, 2018. DOI:10.1016/j.jece.2018.02.020.
[34] A. C. Lua, J. Guo. Preparation and characterization of activated carbons from oil-palms stones for gas-phase adsorption. Colloids and Surfaces A: Physicochemical and Engineering Aspects 179:151-162, 2001. DOI:10.1016/S0927-7757(00)00651-8

[35] S. Niknaddaf, J. D. Atkinson, P. Shariaty, et al. Heel formation during volatile organic compound desorption from activated fiber cloth. Carbon 96:131-138, 2016. DOI:10.1016/j.carbon.2015.09.049.

[36] J. D. Seader, E. J. Henley, D. K. Roper. Separation process principles: Chemical and Biochemical Operation (3rd. ed). John Wiley \& Sons, Inc. The United States, 2011.

[37] T. C. Ezeji, P. M. Karcher, N. Qureshi, H. P. Blaschek. Improving performance of a gas stripping-based recovery system to remove butanol from Clostridium beijerinckii fermentation. Bioprocess and Biosystems Engineering 27(3):207-214, 2005. DOI:10.1007/s00449-005-0403-7.

[38] P. Liss, P. Slater. Flux of gases across the air-sea interface. Nature 247:181-184, 1974. DOI:10.1038/247181a0

[39] D. Mackay, P. J. Leinonen. Rate of evaporation of low-solubility contaminants from water bodies to atmosphere. Environmental Science \& Technology 9(13):1178-1180, 1975. DOI:10.1021/es60111a012.

[40] C. D. Hodgman, R. C. Weast, R. S. Shankland, et.al. CRC Handbook of chemistry and physics: A readyreference book of chemical and physical data (44th. ed). The Chemical Rubber Publishing, Cleveland, Ohio, 1963. 